\title{
Structural basis of blocking integrin activation and deactivation for anti-inflammation
}

\author{
Eun Jeong Park ${ }^{1,2}$, Yoshikazu Yuki ${ }^{2}$, Hiroshi Kiyono ${ }^{2,3}$ and Motomu Shimaoka ${ }^{1}$
}

\begin{abstract}
Integrins mediate leukocyte accumulation to the sites of inflammation, thereby enhancing their potential as an important therapeutic target for inflammatory disorders. Integrin activation triggered by inflammatory mediators or signaling pathway is a key step to initiate leukocyte migration to inflamed tissues; however, an appropriately regulated integrin deactivation is indispensable for maintaining productive leukocyte migration. While typical integrin antagonists that block integrin activation target the initiation of leukocyte migration, a novel class of experimental compounds has been designed to block integrin deactivation, thereby perturbing the progression of cell migration. Current review discusses the mechanisms by which integrin is activated and subsequently deactivated by focusing on its structure-function relationship.
\end{abstract}

Keywords: Integrin, Affinity, Activation, Deactivation, Leukocyte, Inflammation, Talin, Kindlin

\section{Introduction}

Integrins are the largest family of cell adhesion molecules that mediate cell-to-cell and cell-to-matrix interactions in a broad range of biological phenomenon such as host defense, hemostasis, wound healing, angiogenesis, organ development [3, 29, 43, 63, 73]. These functions are achieved via integrin bidirectional signaling across plasma membrane $[34,55]$. Inside-out signaling takes place upon association of intracellular activators (e.g., talin, kindlins) with integrin cytoplasmic domains, leading to transition of integrin conformation to high affinity for binding ligands. Upon ligand binding, integrins undergo clustering and transmit their outside-in signals to the cytoplasmic domains, leading to forming focal adhesions that connect to actin filaments for many cellular processes. While integrins are expressed virtually in all cell types, a subset of integrins including $\alpha \mathrm{L} \beta 2, \alpha \mathrm{M} \beta 2, \alpha 4 \beta 1$, and $\alpha 4 \beta 7$ are predominantly expressed on leukocytes, thereby regulating immune cell trafficking to lymphoid tissues and sites of inflammation.

\footnotetext{
* Correspondence: epark@doc.medic.mie-u.ac.jp

'Department of Molecular Pathobiology and Cell Adhesion Biology, Mie University Graduate School of Medicine, Mie 514-8507, Japan

${ }^{2}$ Division of Mucosal Immunology, Department of Microbiology and Immunology, The Institute of Medical Science, The University of Tokyo, Tokyo 108-8639, Japan

Full list of author information is available at the end of the article
}

Integrins play a critical role in the regulation of extravasation of leukocytes to sites of inflammation [5, 11, 12]. During rolling along the endothelial cells via selectins, leukocytes encounter chemokines expressed on endothelial cells [87]. The integrin activation by chemokine enables abrupt arrest of cells on endothelial integrin ligands. Subsequently adherent leukocytes leave the initial point of arrest, and, thereby, crawl along the endothelial apical surface to a so-called hot spot where they undergo transmigration across the endothelial cells [69]. Crawling and transendothelial migration (TEM) requires a dynamic balance of up- and down-regulation of cellular adhesiveness that is achieved by not only integrin activation but also properly regulated integrin deactivation [52]. Here we review the molecular mechanisms that regulate integrin activation and deactivation.

\section{Review}

Leukocyte interaction with endothelial cells to enter inflamed tissues

Leukocyte interaction with endothelial cells represents early events during inflammation or immune surveillance and occurs through selectin-mediated rolling, chemokinedriven activation, and integrin-dependent arrest [37, 44, 82]. Binding of chemokines to $G$ protein-coupled receptors (GPCRs) triggers rapid arrest of rolling leukocytes in which leukocyte integrins (e.g., $\alpha \mathrm{L} \beta 2$ or $\alpha 4 \beta 1)$ are activated 
to adhere to the ligands such as intercellular adhesion molecule 1 (ICAM1) or vascular cell-adhesion molecule 1 (VCAM1) on endothelial cells [65]. Leukocytes undergo intravascular crawling via $\alpha M \beta 2-I C A M 1$ interaction until finding the "hot spots" proper for emigrating into inflamed tissues [53]. Leukocyte integrins, $\alpha \mathrm{L} \beta 2$ and $\alpha 4 \beta 1$, interact with junctional adhesion molecules (JAMs) such as JAM-A and JAM-B, respectively, on endothelial cells to facilitate TEM of the leukocytes as a final step in the homing cascade to inflamed tissues [40]. Formation of an endothelial docking structure with actin-based membrane protrusions is thought to raise efficiency of leukocyte TEM during inflammation $[10,45]$.

\section{Structure and conformational regulation of integrins}

Integrins are $\alpha / \beta$ heterodimeric membrane proteins that exhibit a characteristic feature of complex multi-domain organization [76, 77]. Integrins on resting cells are maintained in a default inactive state, in which the headpiece is folded back to the leg pieces [8], thereby exhibiting a bent conformation (Fig. 1a). Of note, the cytoplasmic parts of integrin $\alpha$ and $\beta$ subunits are associated, thereby stabilizing the bent conformation [80]. In this inactive bent conformation, the ligand binding domain is not only oriented unfavorable for interacting with ligand on the opposing cells, but also in the low affinity configuration. Upon integrin activation, the interface between headpiece and tailpiece is opened in a switchblade-like movement, thereby exhibiting an extended conformation, in which the ligand binding headpiece is oriented favorable toward the ligand on the opposing cells [7, 74]. The conversion from the inactive bent conformation to the active extended conformation with open headpiece is triggered by the separation of the $\alpha / \beta$ cytoplasmic domains [34, 79], and is linked to the structural rearrangements in the ligand binding domain that leads to the high-affinity configuration (Fig. 1c). Along the course of activation dependent conformation conversion from the bent conformation to the extended form with open headpiece, an extended form with closed headpiece has been proposed as an intermediate state that possess intermediate affinity to the ligand (Fig. 1b) [7, 74].

Half of the integrin $\alpha$ subunits and all of $\beta$ subunits possess a von Willebrand factor-type A domain, which is also known as an inserted (I) domain [26, 67]. The $\alpha$ I and $\beta$ I domains adopt a Rossmann fold that contains a

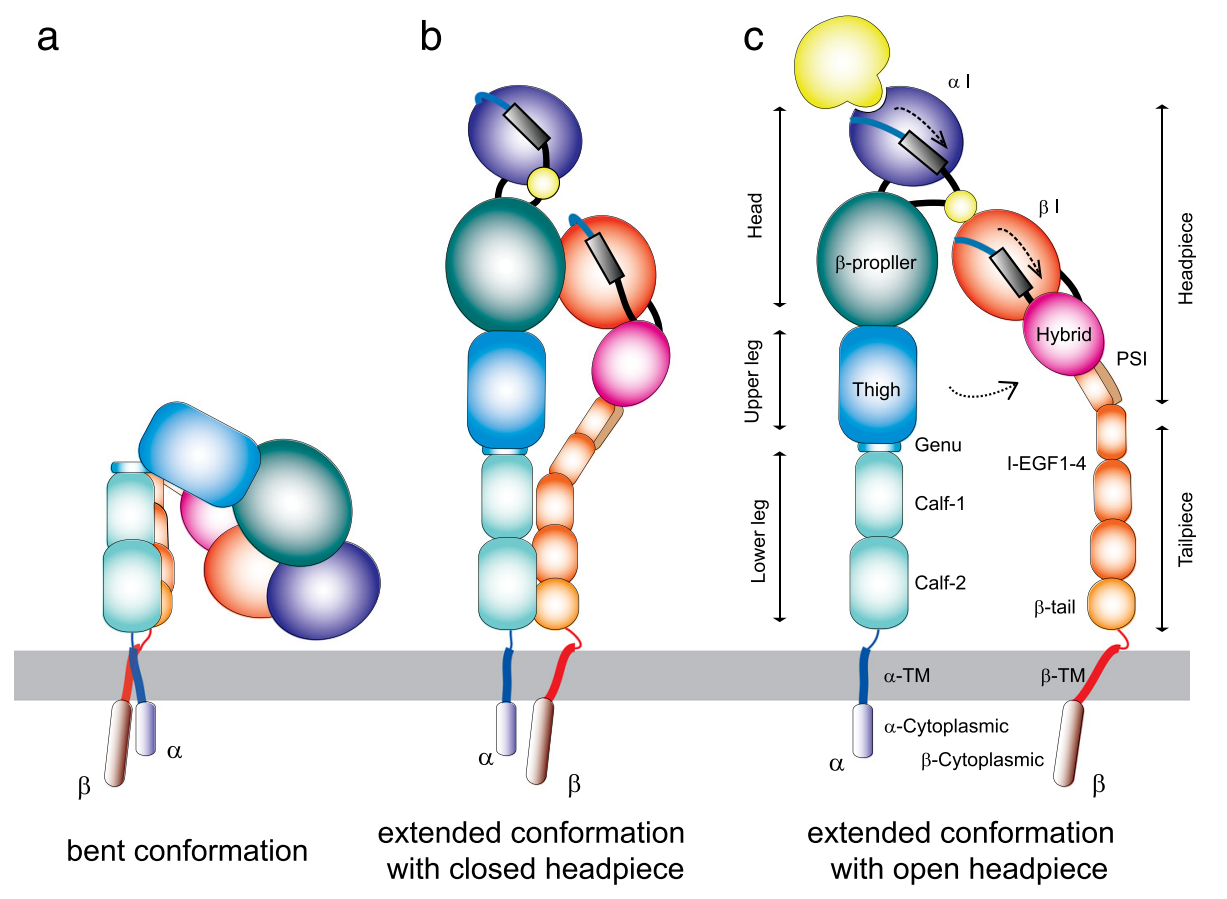

Extrinsic ligand (e.g., ICAM- 1$) \quad$ Intrinsic ligand (e.g., Glu310)
C-terminal $\alpha$-helix of $\alpha$ I and $\beta$ I domains
$\mathrm{N}$ - and C-terminal connections of $\alpha$ I and $\beta$ I domains in which they are inserted

Fig. 1 Different integrin conformations. a Bent conformation containing the closed headpiece (with low-affinity I domain). b Extended conformation containing the closed headpiece (with intermediate-affinity I-domain). c Extended conformation containing the open headpiece (with the high-affinity I domain). I-EGF, integrin-epidermal growth factor; PSI, plexin/semaphorin/integrin; TM, transmembrane 
metal ion-dependent adhesion site (MIDAS) located on the top, whereas its $\mathrm{C}$ - and $\mathrm{N}$-terminal connections located on the distal bottom face $[25,36,67,89]$. The ability of the I domain to bind ligand is regulated by conformational changes. The affinity of the I domain for its ligand is dramatically enhanced by a "piston-like" downward axial displacement of its C-terminal helix. The C-terminal downward shift is conformationally linked to the conversion of the MIDAS to the high-affinity open configuration $[28,66,68,83]$. The C-terminal $\alpha$ helix contains an invariant isoleucine residue at the bottom. The side chain of the invariant isoleucine is deeply embedded to the hydrophobic pocket underneath the helix, thereby acting as a ratchet that prevents the helix from moving down easily. The invariant isoleucine serves as an important intrinsic structural component to maintain a default low-affinity I domain, thereby constituting the mechanisms of integrin deactivation.

The association of the $\alpha$ and $\beta$ integrin cytoplasmic tails functions as a clasp that stabilizes the low-affinity bent conformation. The arginine residue in the GFFKR motif makes a salt bridge with the conserved acidic residue (aspartate or glutamate) at the membrane proximal region of the $\beta$ cytoplasmic domain. The cytoplasmic salt bridge plays a critical role in "clasping" the $\alpha / \beta$ cytoplasmic domains together, thereby serving as another intrinsic structural component to maintain a default low-affinity integrin conformation $[24,38,39]$. The activation of chemokine receptors initiates an intracellular signaling cascade that eventually impinges upon the integrin cytoplasmic tails. Binding to the integrin cytoplasmic domains of adaptor molecules triggers a dissociation of the integrin cytoplasmic tails, thereby triggering integrin activation of the $\beta$ I domain $[9,22,85]$. Activated $\beta$ I domain binds to an intrinsic ligand (a conserved acidic residue) at the linker region connecting to the $\mathrm{C}$-terminal helix of the $\alpha$ I domain [62]. This inter-domain interaction (i.e., binding of the $\beta$ I domain to the intrinsic ligand) facilitates the pulling down the C-terminal helix of the $\alpha$ I domain, thereby inducing the high-affinity open MIDAS conformation of the $\alpha$ I domain that is competent for the external ligand.

\section{Fine-tuning integrin activation and deactivation}

Cell migration requires cycles of integrin activation and deactivation [95]. A simplified view is that at the front of migrating cells integrin activation takes place, thereby mediating cell adhesion, while at the rear of those cells integrin deactivation occurs, thereby facilitating cell deadhesion [47]. Several mechanisms are involved in the regulation of the balance between activation and deactivation, thereby fine-tuning integrin-mediated cell adhesion and migration.
Talin is the cytoplasmic adaptor molecule that plays the central role in triggering integrin activation. Talin is a large, actin-binding, cytoskeletal protein that comprises an N-terminal globular talin head that is connected, via a long unstructured linker, to a C-terminal long tail-like talin rod. The talin head contains 4 FERM domains (F0, F1, F2, and F3) $[19,49]$. The talin head F3 domain contains a primary integrin binding site that directly interact with the integrin $\beta$ cytoplasmic tail. Talin head also binds to the inner surface of the plasma membrane, which is mediated by electrostatic attraction of a cluster of basic residues in talin head domains with acidic plasmamembrane phospholipids such as phosphatidylinositol 4,5bisphosphate (PIP2). To activate integrin only on demand, talin binding to integrin needs to be regulated. In an inactive state, talin adopts the auto-inhibition conformation (Fig. 2a) [13, 18]. The auto-inhibition conformation in talin is released by the presence of PIP2 [84]. This could be made possible through recruitment of talin to PIP2-rich membrane microenvironments that also contain integrins. This pull-push model for talin activation is shown in Fig. 2a. As an alternative to PIP2, some proteases in the cytoplasm such as calpain or metalloproteinase-2 possess a limited proteolysis effect to unmask the auto-inhibition conformation of talin potentially liberating the talin head available for integrin activation [72, 90]. Also, Rap1-RIAM complex plays an important role in chemokine- and TCRtriggered up-regulation of integrin activity in leukocytes. When talin is recruited to the plasma membrane upon cellular signal, RIAM in the Rap1-RIAM complex binds to the talin [91]. This binding activates talin to associate with $\beta$ integrin cytoplasmic tail, which mediates integrin activation (Fig. 2b). The talin F3 domain primarily binds the membrane-proximal NPXY motif of the integrin $\beta$ tail, and then forms a non-covalent interaction with a conserved acidic residue at the membrane proximal region of the integrin $\beta$ tail [4]. The salt bridge helps to stabilize the talin-integrin interaction as well as unclasp the salt bridge formed between the $\alpha$ and $\beta$ integrin cytoplasmic tails (Fig. 2c). Thus, talin appears to utilize the plasma membrane binding as a pivot point to exert a robust effect on the integrin cytoplasmic tail. In this way, talin causes the separation of the integrin $\alpha$ and $\beta$ cytoplasmic tails, thereby triggering integrin activation.

Kindlins (kindlin 1, kindlin 2, and kindlin 3) are another family of FERM domain-containing proteins that are predicted to adopt a similar structure to the talin head. A hematopoietic cell-specific kindlin 3 has been found as an integrin co-activator that cooperates with talin. Kindlin 3 is required for effector T cells in $\alpha 4 \beta 1$ and $\alpha \mathrm{L} \beta 2$ integrin binding to and stabilization of the interaction with ligand, especially at low level of integrin ligand [46]. Kindlin binds to the membrane distal NPXY motif of the $\beta$ cytoplasmic domain, as opposed to talin that binds to the membrane- 


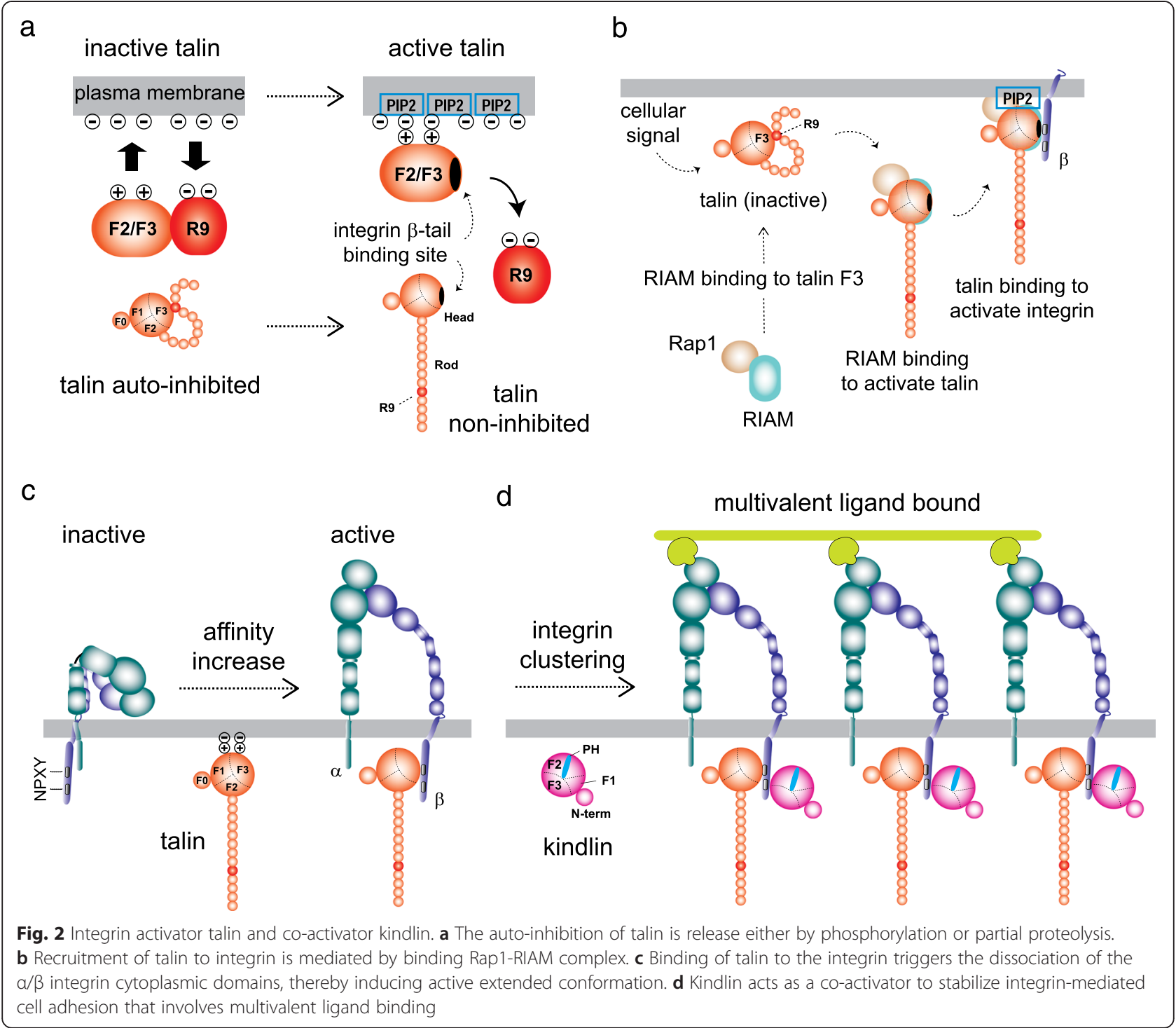

proximal NPXY motif [93]. Kindlin does not compete with talin for integrin and augments multivalent ligand binding capacity by promoting the clustering talinactivated integrins (Fig. 2d) [94]. In contrast to talin, kindlin by itself is unable to induce the separation of the integrin cytoplasmic association. Kindlin rather functions as a co-activator to talin, thereby potentiating talin-mediated integrin activation and cell adhesion [94].

Kindlin 1 is overexpressed in lung and colon carcinomas and hence targeting kindlin 1 can be effective to restrain metastasis in some cancers [71, 86]. Loss-of-function mutations in kindlin1 caused Kindler syndrome (KS) in which the keratinocytes from KS patients had a defect in motility due to impaired activation of $\beta 1$ integrin [23, 35, 70]. Kindlin 2 itself appears to involve in suppressing cancer cell migration [21, 57], although little has been reported for direct evidence on human disease related to the genetic defect in the kindlin 2. An invasive breast cancer cell line (TMX2-28) highly expressed kindlin 2 that played a critical role in cell invasion, since knocking down of kindlin 2 repressed cell invasiveness [20]. Mutations in kindlin 3 cause leukocyte adhesion deficiency (LAD) type-III, a primary immune deficiency that manifests unresponsiveness of agonist-triggered integrin-mediated leukocyte adhesion and platelet aggregation [14, 42, 60, 75]. The kindlin 3 knockout mice exhibited the LAD-III like phenotypes including perturbed integrin-mediated adhesion of leukocytes to endothelial cells [48].

\section{Suppression of integrin activation by interfering with talin binding}

This section describes cytoplasmic molecules that have been shown to interfere with talin binding to integrins, thereby stabilizing the inactive bent conformation. 
Phosphotyrosine-binding (PTB) domain-containing proteins, Dok1 (docking protein 1) and ICAP1 (integrin cytoplasmic domain-associated protein 1), have been shown, like filamin, to compete with talin for binding to the integrin cytoplasmic domain. Dok1 has been shown to bind to the NPXY motif [50]. However, only talin but not Dok1 stabilizes the open active conformation of integrin [85]. The inability to disrupt the clasping salt-bridge makes Dok1 unable to induce the separation of the integrin $\alpha / \beta$ cytoplasmic tails needed for activation. The mode by which Dok1 competes with talin is regulated by integrin tyrosine phosphorylation. Binding of talin, but not of Dok1, in integrin $\beta$ tails is reduced by integrin tyrosine phosphorylation [1]. Thus phosphorylation makes integrin inactive.

SHARPIN (SHANK-associated RH domain-interacting protein) gene mutations naturally occurring in mice were found to cause chronic proliferative dermatitis, a systemic inflammation involving multiple organs [64]. More recently, SHARPIN has been found as an inhibitor of integrin activation that interacts with the $\alpha$ integrin cytoplasmic and, thereby, interferes with talin binding to integrin and subsequent integrin activation [56]. SHARPIN binds to the $\alpha$ integrin membrane proximal region that contains the conserved GFFKR motif to form the clasping salt-bridge with the $\beta$ subunit [56]. SHARPIN binding does not involve the arginine residue in the GFFKR, thereby maintaining the formation of the clasping salt-bridge [56]. Furthermore, SHARPIN binding to the $\alpha$ integrin tail inhibits talin and kindlin binding to the $\beta$ integrin tail presumably through steric hindrance [56]. SHARPIN deficiency has been shown to enhance integrin-mediated cell adhesion and reduce its migration velocity [54]. In addition to its role of inactivating integrins, SHARPIN also functions as an ubiquitin binding protein that plays an important role in the regulation of NF-kB signaling [30]. Thus, chronic inflammation occurred in SHARPIN mutant mice could be due to both aberrant integrin activation and NF- $\mathrm{kB}$ signaling.

\section{Integrin intrinsic components to stabilize the default inactive conformation \\ Cytoplasmic GFFKR motif}

Integrin molecules contain the intrinsic structural components that favor the default bent conformations, thereby preventing spontaneous aberrant integrin activation in the absence of proper stimulatory signals. The cytoplasmic GFFKR motif constitutes an important intrinsic component that facilitates integrin deactivation, thereby favoring a default inactive conformation. Deletion of the GFFKR motif or mutation of the arginine to alanine are designed to disrupt the cytoplasmic salt bridge, and have been shown to make constitutively active integrins as a result of impaired deactivation (Fig. 3a).
Physiological importance of such integrin deactivation in immune cells has been studied using knock-in mice carrying the mutant $\alpha \mathrm{L}$ subunit lacking the GFFKR motif $\left(\right.$ GFFKR ${ }^{\mathrm{d} / \mathrm{d}}$; Lfa-1 ${ }^{\mathrm{d} / \mathrm{d}}$ ) [61]. Lfa- ${ }^{\mathrm{d} / \mathrm{d}}$ lymphocytes express the constitutively active $\alpha \mathrm{L} \beta 2$ that exhibited an impaired integrin deactivation that resulted in persistent cell adhesion but reduced cell migration on ICAM1. When inflammatory response was induced in the peritoneal cavity, Lfa- $1^{\mathrm{d} / \mathrm{d}}$ mice showed less severe accumulation of neutrophils compared with wild-type mice. Lfa- $1^{\mathrm{d} / \mathrm{d}}$ $\mathrm{T}$ cells showed increased contact time with APCs [2]. However, the increased T cell-APC contact time did not induce productive lymphocyte activation and enhanced proliferation but rather resulted in reduced T-cell proliferation. Thus, appropriate balance of $\alpha \mathrm{L} \beta 2$ activation and deactivation appears to be important for optimizing T-cell migration and T cell-APC interactions. Notably, in an allograft heart transplantation model, adoptively transferred Lfa- $1^{\mathrm{d} / \mathrm{d}} \mathrm{T}$ cells exhibited reduced capacity to reject the allograft [27].

The physiological importance of the cytoplasmic salt bridge in the integrin $\alpha 4$ subunit was investigated in another study that utilized knock-in mice that carry a specific point mutation in the $\alpha 4$ integrin GFFKR motif [31]. The mutant knock-in mice termed Itga $4^{\text {GFFKA }}(\alpha 4-\mathrm{R} 974 \mathrm{~A})$ showed impaired deactivation of $\alpha 4 \beta 1$ and $\alpha 4 \beta 7$ integrins [31]. As $\alpha 4 \beta 7$ integrin is an important homing receptor to the gut, $\alpha 4^{\text {GFFKA }}$ mice exhibited a perturbed lymphocyte homing to the gut. On the other hand, naturally occurred mutations in the GFFKR motif of the integrin $\alpha \mathrm{IIb} \beta 3$ subunit have been reported in the patients suffered with congenital macrothrombocytopenia [32]. The platelet integrin $\alpha \operatorname{IIb} \beta 3$ in the patients exhibited constitutively active high-affinity state. This could cause aberrant platelet aggregation and consumption, potentially leading to thrombocytopenia.

\section{Invariant isoleucine residue}

Invariant isoleucine in the $\alpha \mathrm{I}$ domain $\mathrm{C}$-terminal helix is another intrinsic component for deactivation. The isoleucine, through a series of hydrophobic interactions (also known as ratcheting interactions), prevents the $\mathrm{C}$-terminal $\alpha 7$-helix from readily moving down, thereby suppressing the conformational conversion to the high-affinity integrin I domain (Fig. 3b). The knock-in (Lfa- $1^{\text {I306A }}$ or $\left.\alpha \mathrm{L}-\mathrm{I} 306 \mathrm{~A}\right)$ mice were generated that carried a specific point mutation (substitution of the isoleucine to arginine) in the integrin $\alpha \mathrm{L}$ subunit I domain (Fig. $3 \mathrm{~b}$ ) [52]. $\alpha \mathrm{L} \beta 2$ deactivation was impaired in the $\mathrm{Lfa}-1^{\mathrm{I306A}}$ lymphocytes, thereby showing a constitutively active cell adhesion but reduced cell migration on endothelial cells. During migration on ICAM1 substrates, the Lfa- $1^{\text {I306A }}$ lymphocytes exhibited an extremely polarized shape characterized with an abnormally prolonged tail. This is 
a

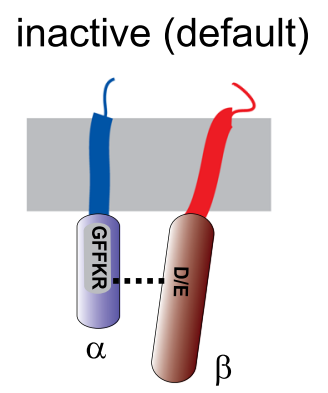

b

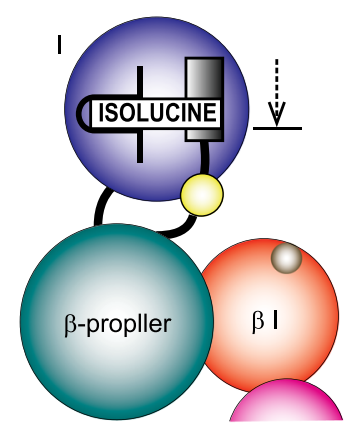

C

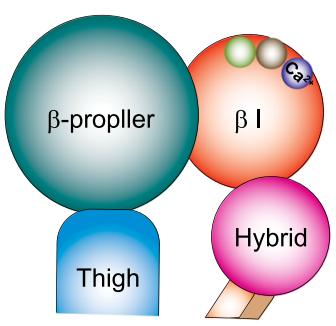

GFFKR Gly-Phe-Phe-Lys-Arg motif
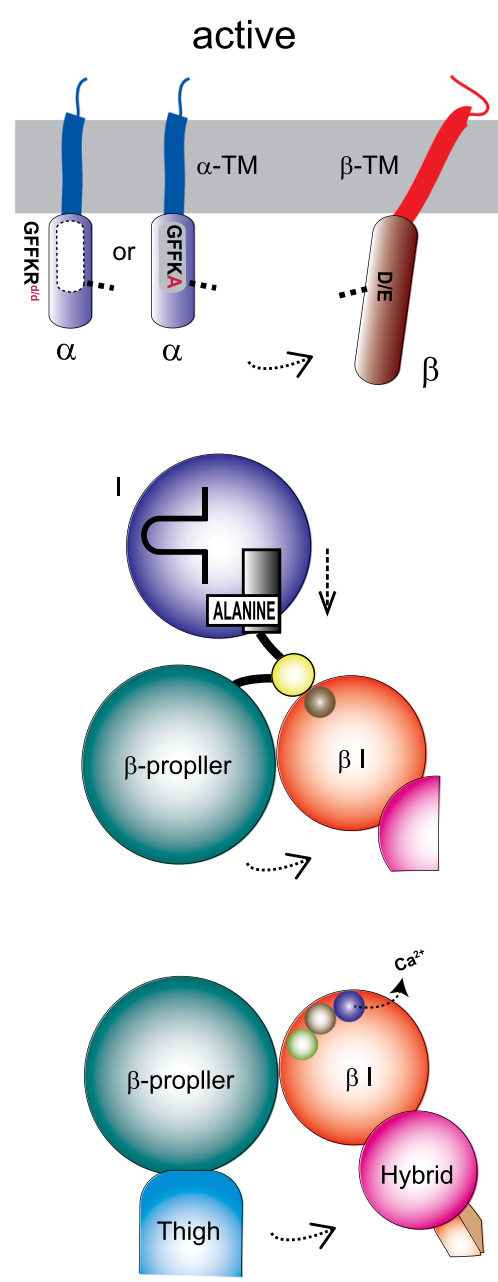

GFFKR d/d $\quad$ GFFKR-deletion mutant $\quad$ D/E Asp or Glu

$\begin{array}{llll}\text { GFFKA } & \text { Point mutation in GFFKR motif (Arg to Ala residue) } \\ \text { OO Inactive and active MIDAS } & \text {...... Salt bridge } \\ \text { OOO } & \text { Metal ion-binding sites (SyMBS, MIDAS, ADMIDAS) }\end{array}$

Fig. 3 Structural components to stabilize inactive integrin conformation. a The cytoplasmic salt bridge is formed between the arginine residue in the a subunit and the glutamate residue in the $\beta$ subunit, thereby clasping the $\alpha / \beta$ integrin cytoplasmic tails. A mutation to disrupt the salt bridge results in promoting the cytoplasmic dissociation, thereby inducing integrin activation. $\mathbf{b} \mathrm{A}$ conserved isoleucine at the $\mathbf{a}$ I domain $\mathrm{C}$-terminal helix acts as a ratchet to stabilize the inactive conformation. A downward shift of the C-terminal helix is mediated by an interdomain interaction by the $\beta$ I domain (also known as I-like domain). $\mathbf{c ~} \mathrm{Ca}^{2+}$ binding site ADMIDAS in the $\beta$ I domain favors the inactive low-affinity integrin headpiece conformation. A mutation to disrupt the $\mathrm{Ca}^{2+}$ binding site induces the constitutively active conformation by facilitating the conformational swing out of the hybrid domain

because the uropod failed to readily detach from the ligand substrates. Detailed two-photon in vivo imaging demonstrated that Lfa- $1^{\mathrm{I} 306 \mathrm{~A}}$ lymphocytes showed enhanced arrest on the surface of the lymph node endothelial cells, but failed to effectively crawl on and transmigrate across the endothelial cells into tissue parenchyma. This implicates the balance of activation and deactivation in regulating integrin-mediated intravascular crawling that constitutes an integral part of immune-surveillance inside the blood vasculature.

\section{ADMIDAS}

Unlike the $\alpha$ I domain, the $\beta$ I domain contains two additional metal binding sites, synergistic metal binding site (SyMBS) and adjacent to MIDAS (ADMIDAS), at the either side of the MIDAS, thereby forming has a linear 
cluster of three metal ion binding sites (Fig. 3c) [58, 88]. Of note, the ADMIDAS that coordinates $\mathrm{Ca}^{2+}$ contributes to stabilizing the $\mathrm{C}$-terminal helix in the low affinity configuration, thereby serving as another intrinsic structural component [6]. The inhibitory effect of $\mathrm{Ca}^{2+}$ to integrins is thought to mediate through its coordination to the ADMIDAS of the $\beta$ I domain. $\mathrm{Ca}^{2+}$ coordination at the ADMIDAS in the $\beta 7$ I domain was disrupted by knocking-in a germline mutation of a functionally key residue (Itgb7 $\left.{ }^{\text {D146A }} ; \beta 7-D 146 A\right)$ (Fig. 3c) [51]. Itgb7 ${ }^{\text {D146A }}$ lymphocytes showed the aberrantly activated $\alpha 4 \beta 7$ integrin that exhibited perturbed migration on MAdCAM-1 substrates. The Itgb7 ${ }^{\mathrm{D} 146 \mathrm{~A}} \mathrm{~T}$ cells showed reduced capacity to home to the gut and, thereby, decreased potential to cause intestinal inflammation in a T-cell transfer colitis model. Thus, in vivo perturbation of integrin deactivation studied in a series of knock-in mice Lfa- ${ }^{\mathrm{d} / \mathrm{d}}, \mathrm{Lfa}-1^{\mathrm{I} 306 \mathrm{~A}}$, Itgb7 $7^{\mathrm{D} 146 \mathrm{~A}}$, and Itga4 ${ }^{\mathrm{GFFKA}}$ all points to the anti-migratory and anti-inflammatory phenotypes. This supports the idea that intervention aiming to interfere with not only integrin activation but also integrin deactivation would make an effective therapeutic approach for anti-inflammation.

\section{Small molecules to modulate integrin activation}

A small molecule agonist of $\alpha \mathrm{L} \beta 2$, compound 4 , showed to act as a facilitator of ICAM1 binding by T cells and a simultaneous inhibitor of TEM in a physiological condition [92]. This was due to the finding that compound 4-mediated $\alpha \mathrm{L} \beta 2$ accumulation in the uropod induced its extreme elongation and the impaired de-adhesion of human lymphocytes. Furthermore, leukadherin, a small molecule agonist of another $\beta 2$ integrin heterodimer $\alpha M \beta 2$, induced the increased $\alpha M \beta 2$ dependent cell adhesion of transfectants and of primary human and mouse neutrophils, and the decreased chemotaxis and TEM [41]. Also, TGF- $\beta$-related growth differentiation factor- 15 (GDF-15) has revealed to be the first cytokine that represses the recruitment of inflammatory leukocytes to inflamed tissues by blocking integrin activation [33].

\section{Conclusions}

The proper balance of activation and deactivation of leukocyte integrins has been shown to be critical for supporting efficient lymphocyte migration and trafficking. We are beginning to understand how the integrin activators (e.g., talin, kindlin) and inactivators (e.g., Dok1, SHARPIN) work together to promote either association or dissociation of the integrin $\alpha / \beta$ cytoplasmic tails, thereby regulating integrin conformational activation. The intramolecular regulatory sites in integrins are essential for deactivation of integrins. The importance of integrin deactivation in immune cell trafficking to sites of inflammation and activation has been shown in a series of knock-in mice, in which the intramolecular integrin regulatory sites are mutationally disabled. Humanized monoclonal antibodies to leukocyte integrins, natalizumab $(\alpha 4)$ and vedolizumab $(\alpha 4 \beta 7)$, were efficacious in treating inflammatory diseases including Crohn's disease and ulcerative colitis [15-17, 59, 78, 81]. Small molecule integrin agonists have been reported that interfere with integrin deactivation, thereby suppressing leukocyte extravasation to inflamed tissues. Blocking integrin deactivation might represent a novel approach to alleviate inflammation.

\section{Competing interests}

The authors declare that they have no competing interests.

\section{Authors' contributions}

EJP and MS wrote the manuscript and made figures, YY and HK commented on the manuscript, and all authors read and approved the final manuscript.

\section{Acknowledgements}

This work was supported by grant from IMSUT Joint Research Project at the Institute of Medical Science in the University of Tokyo, Japan.

\section{Author details}

${ }^{1}$ Department of Molecular Pathobiology and Cell Adhesion Biology, Mie University Graduate School of Medicine, Mie 514-8507, Japan. ${ }^{2}$ Division of Mucosal Immunology, Department of Microbiology and Immunology, The Institute of Medical Science, The University of Tokyo, Tokyo 108-8639, Japan. ${ }^{3}$ International Research and Development Center for Mucosal Vaccine, The Institute of Medical Science, The University of Tokyo, Tokyo 108-8639, Japan.

Received: 17 April 2015 Accepted: 22 June 2015

Published online: 08 July 2015

\section{References}

1. Anthis NJ, Haling JR, Oxley CL, Memo M, Wegener KL, Lim CJ, et al. Beta integrin tyrosine phosphorylation is a conserved mechanism for regulating talin-induced integrin activation. The Journal of biological chemistry. 2009:284(52):36700-10.

2. Balkow S, Heinz S, Schmidbauer P, Kolanus W, Holzmann B, Grabbe S, et al. LFA-1 activity state on dendritic cells regulates contact duration with $T$ cells and promotes T-cell priming. Blood. 2010;116(11):1885-94.

3. Bokel C, Brown NH. Integrins in development: moving on, responding to, and sticking to the extracellular matrix. Dev Cell. 2002;3(3):311-21.

4. Calderwood DA, Campbell ID, Critchley DR. Talins and kindlins: partners in integrin-mediated adhesion. Nat Rev Mol Cell Biol. 2013;14(8):503-17.

5. Campbell DJ, Butcher EC. Rapid acquisition of tissue-specific homing phenotypes by CD4(+) T cells activated in cutaneous or mucosal lymphoid tissues. J Exp Med. 2002;195:135-41.

6. Chen JF, Salas A, Springer TA. Bistable regulation of integrin adhesiveness by a bipolar metal ion cluster. Nat Struct Biol. 2003;10:995-1001.

7. Chen X, Xie C, Nishida N, Li Z, Walz T, Springer TA. Requirement of open headpiece conformation for activation of leukocyte integrin alphaXbeta2. Proc Natl Acad Sci U S A. 2010;107(33):14727-32.

8. Choi WS, Rice WJ, Stokes DL, Coller BS. Three-dimensional reconstruction of intact human integrin alphallbbeta3: new implications for activation-dependent ligand binding. Blood. 2013;122(26):4165-71.

9. Cole KE, Strick CA, Paradis TJ, Ogborne KT, Loetscher M, Gladue RP, et al. Interferon-inducible T cell a chemoattractant (I-TAC): a novel non-ELR CXC chemokine with potent activity on activated T cells through selective high affinity binding to CXCR3. J Exp Med. 1998;187:2009-21.

10. Denucci CC, Mitchell JS, Shimizu Y. Integrin function in T-cell homing to lymphoid and nonlymphoid sites: getting there and staying there. Crit Rev Immunol. 2009;29(2):87-109.

11. Do JS, Visperas A, Freeman ML, Iwakura Y, Oukka M, Min B. Colitogenic effector T cells: roles of gut-homing integrin, gut antigen specificity and gammadelta T cells. Immunol Cell Biol. 2014;92(1):90-8.

12. Doll $K$, Sickinger M, Seeger T. New aspects in the pathogenesis of abomasal displacement. Veterinary journal. 2009;181(2):90-6.

13. Ellis SJ, Goult BT, Fairchild MJ, Harris NJ, Long J, Lobo P, et al. Talin autoinhibition is required for morphogenesis. Curr Biol. 2013;23(18):1825-33. 
14. Fagerholm SC, Lek HS, Morrison VL. Kindlin-3 in the immune system. American journal of clinical and experimental immunology. 2014;3(1):37-42.

15. Feagan BG, Greenberg GR, Wild G, Fedorak RN, Pare P, McDonald JW, et al. Treatment of ulcerative colitis with a humanized antibody to the alpha4beta7 integrin. N Engl J Med. 2005;352(24):2499-507.

16. Ghosh S, Goldin E, Gordon FH, Malchow HA, Rask-Madsen J, Rutgeerts P, et al. Natalizumab for active Crohn's disease. N Engl J Med. 2003;348:24-32.

17. Gordon FH, Hamilton MI, Donoghue S, Greenlees C, Palmer T, Rowley-Jones D, et al. A pilot study of treatment of active ulcerative colitis with natalizumab, a humanized monoclonal antibody to alpha-4 integrin. Aliment Pharmacol Ther. 2002;16(4):699-705.

18. Goult BT, Bate N, Anthis NJ, Wegener KL, Gingras AR, Patel B, et al. The structure of an interdomain complex that regulates talin activity. The Journal of biological chemistry. 2009;284(22):15097-106.

19. Goult BT, Xu XP, Gingras AR, Swift M, Patel B, Bate N, et al. Structural studies on full-length talin1 reveal a compact auto-inhibited dimer: implications for talin activation. J Struct Biol. 2013;184(1):21-32

20. Gozgit JM, Pentecost BT, Marconi SA, Otis CN, Wu C, Arcaro KF. Use of an aggressive MCF-7 cell line variant, TMX2-28, to study cell invasion in breast cancer. Molecular cancer research : MCR. 2006;4(12):905-13.

21. Guo B, Gao J, Zhan J, Zhang H. Kindlin-2 interacts with and stabilizes EGFR and is required for EGF-induced breast cancer cell migration. Cancer Lett. 2015;361(2):271-81.

22. Harburger DS, Bouaouina M, Calderwood DA. Kindlin-1 and -2 directly bind the C-terminal region of beta integrin cytoplasmic tails and exert integrin-specific activation effects. The Journal of biological chemistry. 2009;284(17):11485-97.

23. Herz C, Aumailley M, Schulte C, Schlotzer-Schrehardt U, Bruckner-Tuderman L, Has C. Kindlin-1 is a phosphoprotein involved in regulation of polarity, proliferation, and motility of epidermal keratinocytes. The Journal of biological chemistry. 2006;281(47):36082-90.

24. Hibbs ML, Xu H, Stacker SA, Springer TA. Regulation of adhesion to ICAM-1 by the cytoplasmic domain of LFA-1 integrin b subunit. Science. 1991;251:1611-3.

25. Huang C, Zang Q, Takagi J, Springer TA. Structural and functional studies with antibodies to the integrin b2 subunit: a model for the I-like domain. J Biol Chem. 2000;275:21514-24.

26. Humphries MJ. Integrin structure. Biochem Soc Trans. 2000;28(4):311-39.

27. Huser N, Fasan A, Semmrich M, Schmidbauer P, Holzmann B, Laschinger M. Intact LFA-1 deactivation promotes T-cell activation and rejection of cardiac allograft. Int Immunol. 2010;22(1):35-44.

28. Huth JR, Olejniczak ET, Mendoza R, Liang H, Harris EA, Lupher Jr ML, et al. NMR and mutagenesis evidence for an I domain allosteric site that regulates lymphocyte function-associated antigen 1 ligand binding. Proc Natl Acad Sci U S A. 2000;97(10):5231-6.

29. Hynes RO. A reevaluation of integrins as regulators of angiogenesis. Nat Med. 2002;8:918-21.

30. Ikeda F, Deribe YL, Skanland SS, Stieglitz B, Grabbe C, Franz-Wachtel M, et al. SHARPIN forms a linear ubiquitin ligase complex regulating NF-kappaB activity and apoptosis. Nature. 2011;471(7340):637-41.

31. Imai $Y$, Park EJ, Peer D, Peixoto A, Cheng G, von Andrian UH, et al. Genetic perturbation of the putative cytoplasmic membrane-proximal salt bridge aberrantly activates \{alpha\}4 integrins. Blood. 2008;112(13):5007-15.

32. Kashiwagi H, Kunishima S, Kiyomizu K, Amano Y, Shimada H, Morishita M, et al. Demonstration of novel gain-of-function mutations of alphallbbeta3: association with macrothrombocytopenia and glanzmann thrombasthenialike phenotype. Molecular genetics \& genomic medicine. 2013;1(2):77-86.

33. Kempf T, Zarbock A, Widera C, Butz S, Stadtmann A, Rossaint J, et al. GDF-15 is an inhibitor of leukocyte integrin activation required for survival after myocardial infarction in mice. Nat Med. 2011;17(5):581-8.

34. Kim M, Carman CV, Springer TA. Bidirectional transmembrane signaling by cytoplasmic domain separation in integrins. Science. 2003;301:1720-5.

35. Lai-Cheong JE, Liu L, Sethuraman G, Kumar R, Sharma VK, Reddy SR, et al. Five new homozygous mutations in the KIND1 gene in Kindler syndrome. The Journal of investigative dermatology. 2007;127(9):2268-70.

36. Lee J-O, Rieu P, Arnaout MA, Liddington R. Crystal structure of the a domain from the a subunit of integrin CR3 (CD11b/CD18). Cell. 1995;80:631-8.

37. Ley K, Laudanna C, Cybulsky MI, Nourshargh S. Getting to the site of inflammation: the leukocyte adhesion cascade updated. Nat Rev Immunol. 2007;7(9):678-89.

38. Lu C, Springer TA. The a subunit cytoplasmic domain regulates the assembly and adhesiveness of integrin lymphocyte function-associated antigen-1 (LFA-1). J Immunol. 1997;159:268-78.
39. Lu C, Takagi J, Springer TA. Association of the membrane-proximal regions of the $a$ and b subunit cytoplasmic domains constrains an integrin in the inactive state. J Biol Chem. 2001;276(18):14642-8.

40. Luissint AC, Nusrat A, Parkos CA. JAM-related proteins in mucosal homeostasis and inflammation. Semin Immunopathol. 2014;36(2):211-26.

41. Maiguel D, Faridi MH, Wei C, Kuwano Y, Balla KM, Hernandez D, et al. Small molecule-mediated activation of the integrin CD11b/CD18 reduces inflammatory disease. Sci Signal. 2011;4(189):ra57.

42. Malinin NL, Zhang L, Choi J, Ciocea A, Razorenova O, Ma YQ, et al. A point mutation in KINDLIN3 ablates activation of three integrin subfamilies in humans. Nat Med. 2009;15(3):313-8.

43. Margadant C, Sonnenberg A. Integrin-TGF-beta crosstalk in fibrosis, cancer and wound healing. EMBO Rep. 2010;11(2):97-105.

44. McIntyre TM, Prescott SM, Weyrich AS, Zimmerman GA. Cell-cell interactions: leukocyte-endothelial interactions. Curr Opin Hematol. 2003;10(2):150-8.

45. Mooren OL, Li J, Nawas J, Cooper JA. Endothelial cells use dynamic actin to facilitate lymphocyte transendothelial migration and maintain the monolayer barrier. Mol Biol Cell. 2014;25(25):4115-29.

46. Moretti FA, Moser M, Lyck R, Abadier M, Ruppert R, Engelhardt B, et al. Kindlin-3 regulates integrin activation and adhesion reinforcement of effector T cells. Proc Natl Acad Sci U S A. 2013;110(42):17005-10.

47. Morin NA, Oakes PW, Hyun YM, Lee D, Chin YE, King MR, et al. Nonmuscle myosin heavy chain IIA mediates integrin LFA-1 de-adhesion during T lymphocyte migration. J Exp Med. 2008;205(1):195-205.

48. Moser M, Bauer M, Schmid S, Ruppert R, Schmidt S, Sixt M, et al. Kindlin-3 is required for beta2 integrin-mediated leukocyte adhesion to endothelial cells. Nat Med. 2009;15(3):300-5.

49. Moser M, Legate KR, Zent R, Fassler R. The tail of integrins, talin, and kindlins. Science. 2009;324(5929):895-9.

50. Oxley CL, Anthis NJ, Lowe ED, Vakonakis I, Campbell ID, Wegener KL. An integrin phosphorylation switch: the effect of beta3 integrin tail phosphorylation on Dok1 and talin binding. The Journal of biological chemistry. 2008;283(9):5420-6.

51. Park EJ, Mora JR, Carman CV, Chen J, Sasaki Y, Cheng G, et al. Aberrant activation of integrin alpha(4)beta(7) suppresses lymphocyte migration to the gut. J Clin Invest. 2007;117(9):2526-38.

52. Park EJ, Peixoto A, Imai Y, Goodarzi A, Cheng G, Carman CV, et al. Distinct roles for LFA-1 affinity regulation during T-cell adhesion, diapedesis, and interstitial migration in lymph nodes. Blood. 2010;115(8):1572-81.

53. Phillipson M, Heit B, Colarusso P, Liu L, Ballantyne CM, Kubes P. Intraluminal crawling of neutrophils to emigration sites: a molecularly distinct process from adhesion in the recruitment cascade. J Exp Med. 2006;203(12):2569-75.

54. Pouwels J, De Franceschi N, Rantakari P, Auvinen K, Karikoski M, Mattila E, et al. SHARPIN regulates uropod detachment in migrating lymphocytes. Cell reports. 2013;5(3):619-28.

55. Qin J, Vinogradova O, Plow EF. Integrin bidirectional signaling: a molecular view. PLoS Biol. 2004;2(6), e169.

56. Rantala JK, Pouwels J, Pellinen T, Veltel S, Laasola P, Mattila E, et al. SHARPIN is an endogenous inhibitor of beta1-integrin activation. Nat Cell Biol. 2011;13(11):1315-24.

57. Ren $Y$, Jin H, Xue Z, Xu Q, Wang S, Zhao G, Huang J, Huang H. Kindlin-2 inhibited the growth and migration of colorectal cancer cells. Tumour biology: the journal of the International Society for Oncodevelopmental Biology and Medicine, 2015. [Epub ahead of print] PMID:25633062.

58. Rui X, Mehrbod M, Van Agthoven JF, Anand S, Xiong JP, Mofrad MR, et al. The alpha-subunit regulates stability of the metal ion at the ligand-associated metal ion-binding site in beta3 integrins. The Journal of biological chemistry. 2014;289(33):23256-63.

59. Sandborn WJ, Colombel JF, Enns R, Feagan BG, Hanauer SB, Lawrance IC, et al. International efficacy of natalizumab as active Crohn's therapy trial G. And evaluation of natalizumab as continuous therapy trial G. Natalizumab induction and maintenance therapy for Crohn's disease. N Engl J Med. 2005;353(18):1912-25.

60. Schmidt S, Nakchbandi I, Ruppert R, Kawelke N, Hess MW, Pfaller K, et al. Kindlin-3-mediated signaling from multiple integrin classes is required for osteoclast-mediated bone resorption. J Cell Biol. 2011;192(5):883-97.

61. Semmrich M, Smith A, Feterowski C, Beer S, Engelhardt B, Busch DH, et al. Importance of integrin LFA-1 deactivation for the generation of immune responses. J Exp Med. 2005;201:1987-98.

62. Sen M, Yuki K, Springer TA. An internal ligand-bound, metastable state of a leukocyte integrin, alphaXbeta2. J Cell Biol. 2013;203(4):629-42. 
63. Serini G, Valdembri D, Bussolino F. Integrins and angiogenesis: a sticky business. Exp Cell Res. 2006;312(5):651-8.

64. Seymour RE, Hasham MG, Cox GA, Shultz LD, Hogenesch H, Roopenian DC, et al. Spontaneous mutations in the mouse Sharpin gene result in multiorgan inflammation, immune system dysregulation and dermatitis. Genes and immunity. 2007:8(5):416-21.

65. Shamri R, Grabovsky V, Gauguet JM, Feigelson S, Manevich E, Kolanus W, et al. Lymphocyte arrest requires instantaneous induction of an extended LFA-1 conformation mediated by endothelium-bound chemokines. Nat Immunol. 2005;6:497-506.

66. Shimaoka M, Lu C, Palframan R, von Andrian UH, Takagi J, Springer TA. Reversibly locking a protein fold in an active conformation with a disulfide bond: integrin aL I domains with high affinity and antagonist activity in vivo. Proc Natl Acad Sci U S A. 2001;98:6009-14.

67. Shimaoka M, Takagi J, Springer TA. Conformational regulation of integrin structure and function. Annu Rev Biophys Biomol Struct. 2002;31:485-516.

68. Shimaoka M, Xiao T, Liu J-H, Yang Y, Dong Y, Jun C-D, et al. Structures of the aL I domain and its complex with ICAM-1 reveal a shape-shifting pathway for integrin regulation. Cell. 2003;1 12:99-111.

69. Shulman Z, Shinder V, Klein E, Grabovsky V, Yeger O, Geron E, et al. Lymphocyte crawling and transendothelial migration require chemokine triggering of high-affinity LFA-1 integrin. Immunity. 2009;30(3):384-96.

70. Siegel DH, Ashton GH, Penagos HG, Lee JV, Feiler HS, Wilhelmsen KC, et al. Loss of kindlin-1, a human homolog of the Caenorhabditis elegans actinextracellular-matrix linker protein UNC-112, causes Kindler syndrome. Am J Hum Genet. 2003;73(1):174-87.

71. Sin S, Bonin F, Petit V, Meseure D, Lallemand F, Bieche I, et al. Role of the focal adhesion protein kindlin-1 in breast cancer growth and lung metastasis. J Natl Cancer Inst. 2011:103(17):1323-37.

72. Soslau G, Mason C, Lynch S, Benjamin J, Ashak D, Prakash JM, et al. Intracellular matrix metalloproteinase-2 (MMP-2) regulates human platelet activation via hydrolysis of talin. Thromb Haemost. 2014;111(1):140-53.

73. Springer TA. Traffic signals for lymphocyte recirculation and leukocyte emigration: the multi-step paradigm. Cell. 1994;76:301-14.

74. Stanley P, Smith A, McDowall A, Nicol A, Zicha D, Hogg N. Intermediateaffinity LFA-1 binds alpha-actinin-1 to control migration at the leading edge of the T cell. The EMBO journal. 2008;27(1):62-75.

75. Svensson L, Howarth K, McDowall A, Patzak I, Evans R, Ussar S, et al. Leukocyte adhesion deficiency-III is caused by mutations in KINDLIN3 affecting integrin activation. Nat Med. 2009;15(3):306-12.

76. Takagi J, Erickson HP, Springer TA. C-terminal opening mimics "inside-out" activation of integrin a5b1. Nature Struct Biol. 2001;8(5):412-6.

77. Takagi J, Petre BM, Walz T, Springer TA. Global conformational rearrangements in integrin extracellular domains in outside-in and inside-out signaling. Cell. 2002;110:599-611.

78. Targan SR, Feagan BG, Fedorak RN, Lashner BA, Panaccione R, Present DH, et al. International Efficacy of Natalizumab in Crohn's Disease R. and Remission Trial G. Natalizumab for the treatment of active Crohn's disease: results of the ENCORE Trial. Gastroenterology. 2007;132(5):1672-83.

79. Vinogradova O, Vaynberg J, Kong X, Haas TA, Plow EF, Qin J. Membranemediated structural transitions at the cytoplasmic face during integrin activation. Proc Natl Acad Sci U S A. 2004;101:4094-9.

80. Vomund AN, Stuhlsatz-Krouper S, Dimitry J, Song Y, Frazier WA. A naturally occurring extracellular alpha-beta clasp contributes to stabilization of beta3 integrins in a bent, resting conformation. Biochemistry. 2008:47(44):11616-24.

81. von Andrian UH, Engelhardt B. Alpha4 integrins as therapeutic targets in autoimmune disease. N Engl J Med. 2003;348(1):68-72.

82. von Andrian UH, Mackay CR. T-cell function and migration. Two sides of the same coin. N Engl J Med. 2000;343(14):1020-34.

83. Vorup-Jensen T, Ostermeier C, Shimaoka M, Hommel U, Springer TA. Structure and allosteric regulation of the aXb2 integrin I domain. Proc Natl Acad Sci U S A. 2003;100:1873-8.

84. Wang JH. Pull and push: talin activation for integrin signaling. Cell Res. 2012;22(11):1512-4.

85. Wegener KL, Partridge AW, Han J, Pickford AR, Liddington RC, Ginsberg MH, et al. Structural basis of integrin activation by talin. Cell. 2007;128(1):171-82.

86. Weinstein EJ, Bourner M, Head R, Zakeri H, Bauer C, Mazzarella R. URP1: a member of a novel family of PH and FERM domain-containing membraneassociated proteins is significantly over-expressed in lung and colon carcinomas. Biochim Biophys Acta. 2003:1637(3):207-16.
87. Wurbel MA, Malissen M, Guy-Grand D, Malissen B, Campbell JJ. Impaired accumulation of antigen-specific CD8 lymphocytes in chemokine CCL25-deficient intestinal epithelium and lamina propria. J Immunol. 2007;178(12):7598-606.

88. Xia W, Springer TA. Metal ion and ligand binding of integrin alpha5beta1. Proc Natl Acad Sci U S A. 2014;111(50):17863-8.

89. Xiong J-P, Stehle T, Diefenbach B, Zhang R, Dunker R, Scott DL, et al. Crystal structure of the extracellular segment of integrin $\mathrm{aVb} 3$. Science. 2001;294(5541):339-45.

90. Yan B, Calderwood DA, Yaspan B, Ginsberg MH. Calpain cleavage promotes talin binding to the b3 integrin cytoplasmic domain. J Biol Chem. 2001;276:28164-70.

91. Yang J, Zhu L, Zhang H, Hirbawi J, Fukuda K, Dwivedi P, et al. Conformational activation of talin by RIAM triggers integrin-mediated cell adhesion. Nat Commun. 2014;5:5880.

92. Yang W, Carman CV, Kim M, Salas A, Shimaoka M, Springer TA. A small molecule agonist of an integrin, alphaLbeta2. The Journal of biological chemistry. 2006;281(49):37904-12.

93. Yates LA, Fuzery AK, Bonet R, Campbell ID, Gilbert RJ. Biophysical analysis of Kindlin-3 reveals an elongated conformation and maps integrin binding to the membrane-distal beta-subunit NPXY motif. The Journal of biological chemistry. 2012;287(45):37715-31.

94. Ye F, Petrich BG. Kindlin: helper, co-activator, or booster of talin in integrin activation? Curr Opin Hematol. 2011;18(5):356-60.

95. Zarbock A, Kempf T, Wollert KC, Vestweber D. Leukocyte integrin activation and deactivation: novel mechanisms of balancing inflammation. J Mol Med. 2012;90(4):353-9.

\section{Submit your next manuscript to BioMed Central and take full advantage of:}

- Convenient online submission

- Thorough peer review

- No space constraints or color figure charges

- Immediate publication on acceptance

- Inclusion in PubMed, CAS, Scopus and Google Scholar

- Research which is freely available for redistribution 